\title{
Contemplation on the Ideological and Political Education of Students in Higher Education in New-Media Era
}

\author{
Wang Xiaomei ${ }^{1, a}$ \\ ${ }^{1}$ College of Sciences and Humanities of Northeast Normal University, Changchun, Jilin Province, \\ China 130117 \\ a17048972@qq.com
}

Keywords: New media; Students of higher education; Ideological and political education

\begin{abstract}
Ideological and political education is an indispensable part of higher education and can exert long-term influence on students' outlook on life and value. With the coming of new-media era, the new circumstance exerts new task and requirements. Since the new-media era possesses the characteristics of self-initiative, freedom, openness, efficiency and multi perspectives, thus it brings certain opportunities and also challenges as well. It deserves in-depth exploration into the problems that occur in such education with the adoption of new-media and the results will be implanted into the ideological and political education. It will eventually broaden the vision of the teachers of political education in universities and colleges and students in view of ideological and political education, which thus finally promotes the political education to a higher level.
\end{abstract}

\section{Introduction}

Essentially, new media represents the latest stage of media development that contains such social communicative arenas including blog, microblog, WeChat, QQ, Renren, video net, etc. University students as the receivers of advanced technologies, prefer them much more. However, the influence brought by new media is multi- faceted and of various depths. Therefore, the increasing development of new media calls for new contents. Since the students of universities and colleges represent the future of our nation, then the issue of how the internet is implemented in transmitting the socialist core values, advancing socialist main ideologies, conquering the negative impact brought by new media and guaranteeing the main ideologies occupying and dominating the mind of students has become a radical focus. Therefore, enhancing the ideological and political teaching against the background of new media circumstance exerts great guiding significance to us as the forefront educators.

\section{Basic Situation}

The $18^{\text {th }}$ Report of CPC clearly pinpoints that "strengthening moral education and and cultivating people is the fundamental task that prescribes the people-oriented principle and lays emphasis on moral cultivation, which thus eventually strengthens students' sense of social responsibility, cultivates their innovative spirit and enhance the corresponding practical skills. Thus it endows the new connotation on national education and eventually enlightens the ideological and political education. Chairman Xi emphasized on the national ideological and political conference held in December in 2016, " the ideological and political conference is concerned about the fundamental issues, that is, kind of talent that is to be cultivated, the way of cultivation and for whom the cultivation is conducted. We need to insist on strengthening moral education and cultivating people as the centre phase, and take such education as as the center of the whole process, realizing the cultivating throughout the whole process featuring all-around and therefore creating the new situation for higher education. With the increasing development of science and technology as well as the development of society, the ideological and political education are facing many challenges from various aspects in implementing the fundamental mission of establishing morality and cultivating people. New media, among those new challenges, is the most influential one. Essentially, new media represents new development that includes blog, microblog, WeChat, QQ, Renren, video 
websites, etc. Students of higher education as the receivers of high-tech, prefer the new media, but one point that deserves our attention, that is, the influence brought by the new media is of multi-aspects and depth. Therefore, the increasing development of new media proposes new contents for the education. Leading students to identify and practice social core values is the focus which requires the implanting the social core values into the mind of students with focus on "detail, small, practice".

\section{The Analyses of Circumstance in Ideological and Political Teaching in Higher Education and Existing Problems}

New media possesses its own remarking characteristics. The openness and high efficiency of new media environment. Against such circumstance, every one can become a spoke person and express his or her thoughts on the internet anywhere, any time with incapability of the supervising institution to have access to the news thoroughly. There exists the virtuality and freedom since the new media circumstance can allow the communication with the proponent's real or fake name exposed to the public, which thus significantly reduces the truthfulness of the information. New media information is of various meaningfulness and characteristic. New media conducts its transmission of information through the mass data source and such a great amount of information varies in content. Against the new media background, the educator are facing a great number of challenges. In order to obtain the first-hand materials, the author designed and distributed the survey of ideological and political education in Jilin Province with Jilin as the center of study. This survey starts from the perspective of university students and ideological and political education and conducts the research from the hard-solving problems in promoting the ideological and political education. 200 questionnaires were distributed to universities and colleges in Jilin, among which 185 effective ones are analyzed and the results are shown in Fig. 2-1 as follows:

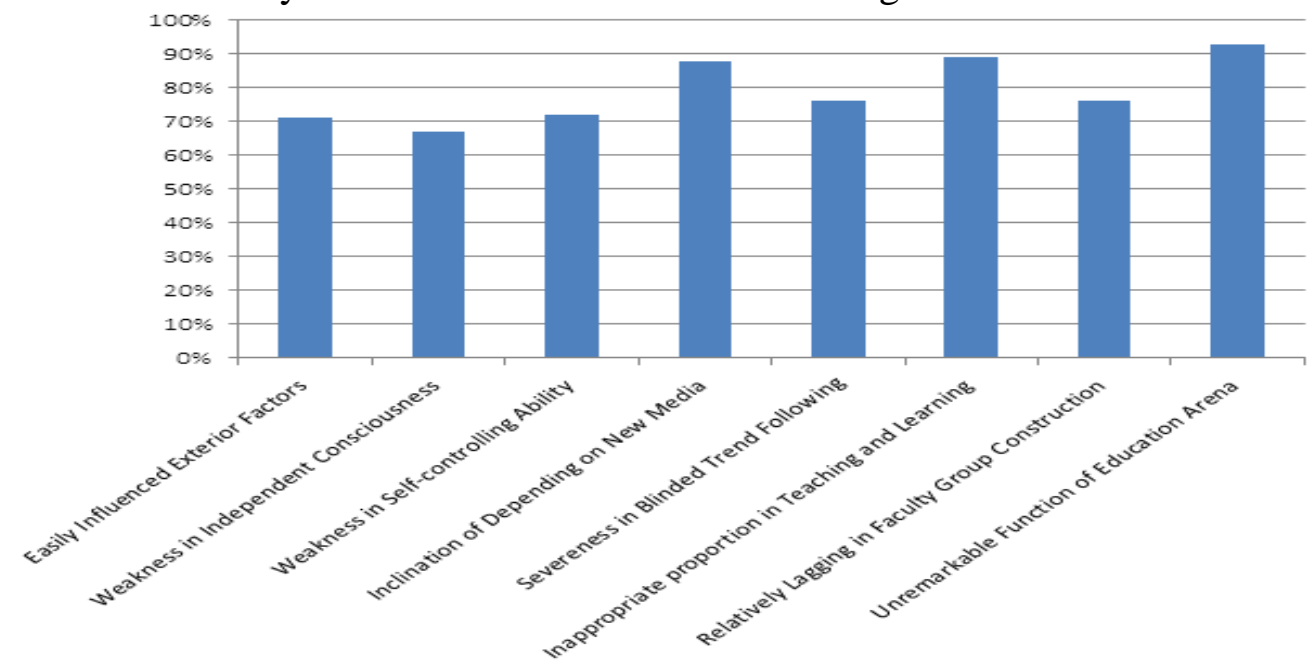

Figure 2-1. Finite Questionnaire Investigation of Ideological and Political Education in Jilin Higher Education

Based on the results of questionnaire investigation, the author summarizes the existing problems as follows:

New-Media Era Influences Students' study. In the new media, the boundary between the true world and virtual world becomes ambiguous, and the physical reality and creative reality are connected, which transforms cognitive methodology of university students fundamentally, and unconsciously deprives the youth of their sense of independence. It therefore to some extent results in the "virtue space" and thus renders the youth to receive enforcing impact and passive influence, finally losing reason and self. They are easily to receive the exterior information and therefore narrow down their own thoughts, thus weakening the mind and imagination. They lack their own theoretical system and mind while analyzing and solving the problems. 
New Media Influences Students' Social life and Communication. The adoption of new media will exert certain negative influence on teachers and students. Students of higher education do not have desirable self controlling ability, and overusing and depending on new media will cause the addiction to the media like obsession with the internet and self-hiding into the virtual world, isolated from the real world. With time going by, they will finally become solitary, indifferent, of low mood, anguished and repressed. Some of students are doubtful towards parents, social dating people and media, which results in inability of establishing interpersonal communication among people. Some are self-absorbed in the virtual communication while isolating from the concrete communication, thus causing social communication disorder and further developing running away from reality. Some are obsessed with the virtual space, which easily produces a series of psychological problems like tension, solitary, escaping from the reality and finally inevitably losing self. Surfing the internet has become the main distribution of students' cultural life, and the invested time has taken up much of their spare life, which reduces the variety of their after-school life.

New Media Influences Students' Thoughts. The new media changes traditional mode of previous fashioned media that features providing single type of information, thus congregating various information (text, picture, animation, audio, video), various transmitting channels(internet, satellite, earth), various receiving termination ( computer, TV, cellphone, PDA), all of which provide potential opportunities to ideological and political education. Simultaneously, higher education, as the converging center of various thoughts and cultures at home and abroad, where western cultures and living modes are competing against the national culture and conventional living mode unprecedentedly. When some unenlightened, corrupted thoughts and cultures and even some anti-socialism, anti-marxism tones and capitalistic negative thoughts and cultures are penetrating, some information that defies social morality has been spread with the use of new media, thus disturbing the main stream thoughts in education and necessarily bringing severe challenges to the cultivation as a whole.

\section{The Speculation over the Strategies in Ideological and Political Education of Students of Higher Education in New Media Era}

Change the Ideas of Ideological And political Education. The emergence of new media promotes the development of internet and the use and selection of information in way of automation and freedom has become the reality. Against such circumstance, in order to strengthen the ideological and political education of students, educators must transform their outlook with the respect to students. Practically, they need to change the previous role of "supervisor" to "servant", and also at the same time to realize that "instruction" is the only methodology and its ultimate aim is the "studying" of students. All the ideological and political education are supposed to abide by the principle of satisfying students' needs and actual situation. Understanding students' growing principles and characteristics of their thoughts are the premise; Designating the cultivation and all-round development are the essential aim; respecting the various needs of students and individual distinction are the key modes; leading students to actively participate into the entire process of education. Resource sharing and mutual trust have been realized and harmonious relationship between teachers and students has been constructed, which ultimately enhances the practical effects of ideological and political education.

Strengthen the Establishment of Faculty Group. In order to enhance the morality of university students, the faculty group needs to be strengthened firstly. This is the fundamental guarantee for promoting students' morality. Against such background of new media circumstance, optimizing the faculty group through regular training and enriching their educational skills is the necessity for promoting and cultivating teaching group, which finally benefits students' ideological and political education. A specialized faculty group featuring high moral quality and high moral level with new 
media transmitting ideas and good at using instruments is indispensable. Sharp mind and swift action is necessary to find out and locate the problem without any inappropriate cliche conventions and regulations imposing on students. Furthermore, abiding by the trend of information age and being identified by the students are the necessary factors contributing to the good image establishment as good teachers.

Create the New Arena of Ideological and Political Education. The creation of a new area of ideological and political education will, to a certain extent, stimulate students' interest in studying and cultivating their ability in solving problems. Initially stepping into the internet world by way of internet media including official blog and WeChat to realize the ideological and political education will enable students to participate into hot issue discussion featuring new theme, new topic, eye-catching. Therefore, the communication in thoughts, discussion in leading and congregation will take upper hand potentially and smoothly in influencing students' thoughts. Besides, students will be highly encouraged in new media stage and make the best use of their sources. Various timely political thematic discussions will be schemed with the aim of conducting initiative self education. The establishment of ideological and political education arena aims to cultivate students' ability in self-studying, increasing creative consciousness and enhancing students' innovative ability, shown in Fig. 3.1.

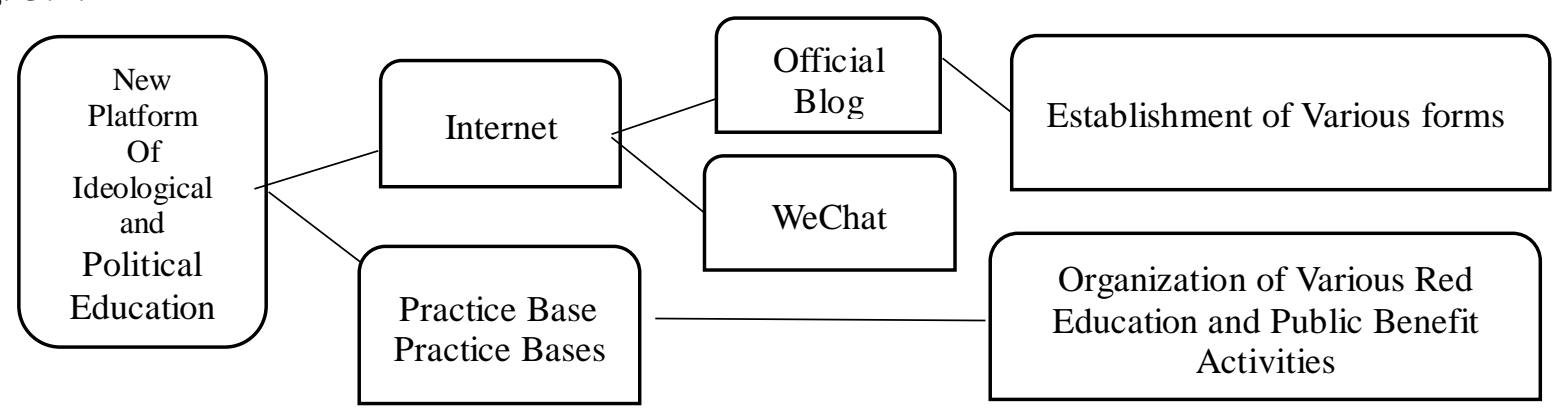

Figure 3-1. Finite Establishment of New Education Stage of Ideological and Political Education in Higher Education

Increase the Supervision of Campus. Against the background of new media, the freedom and go-as -you-please in internet spreading render the university to face difficulties in supervising university students, which however does not necessarily leaves the educators without any solutions. As for the educators in ideological and political education, the adoption of new media in overall new media and technology circumstance will construct relatively enclosed campus net that can filtrate the negative information through inspection and shield in order to reduce the detrimental impact on thoughts and psychology of university students. In addition, a series of resources including instruction, students' information management system, entrance guarding, BBS forum, WeChat public and campus blog are beneficial for congregation of campus media centre that can plan as a whole for campus resources, blog assisting, real name recognition of WeChat, which can extract the internet time, student number, cellphone number and blog account number, etc. Through such kind of supervising system with the assistance of analyzing psychological or internet addiction intention, the ideological and political education will be further developed through judgement and psychological consulting.

Throughout the practical education of higher education, the teaching needs to be conducted by way of active education methods and innovation in contents and methodologies in accordance with the students' information and self features of new media. With the adoption of new media arena, virtual and real methods should be congregated in ideological and political education. The colleges and universities in the higher education field should focus on the construction of multi-media arena through campus internet, campus WeChat, blog and QQ zone in order to successively start out new 
educational methods and create new working mode of ideological and political education mode. Firstly, the educators of ideological and political education are supposes to offer sufficient and various ideological and political education information through the campus new media channel. Simultaneously, they should also strengthen the equal communication with the students in order to promote education efficiently. Secondly, the educators should provide some information on hot issues through personal WeChat, QQ, blog, that they are quite concerned about, like social focus and hot topics, and offer certain analyses as well as their personal ideas and stands in order to influence and lead their students unconsciously. All in all, against the new media circumstance, the abilities of ideological and political educators should be strengthened in order to be adapted to the way of education against new environment. The ideological and political education of students in the universities and colleges will play an important role in the cultivation of talents. Therefore, the conventional teaching mode should be transformed in order to establish a new teaching mode, which will increase students' interest in ideological and political education, stimulate their potential abilities and enhance students' comprehensive ability over-all.

\section{Summary}

The $18^{\text {th }}$ Report of CPC pinpoints the determination of managing well the education that satisfies Chinese people through promoting the connotative development of higher education. Chairman Xi guided in December in 2016 in the National Conference of Ideological and Political Education that "ideological and political education is essentially concerned with human being, which should be closely connected with students, caring about students, serving students in order to ceaselessly enhance students' level of thinking, political awareness, morality and personality, cultural quality and thus to forge students to be the talent of high morality and overall development." Therefore, the ideological and political education plays an important role in higher education. In the new media age, the educators of higher education with the historical perspective should speculate, explore and transform the working ideology and makes the best use of new media arena to conduct certain targeting instruction. While actively constructing the main educating field, teachers should actively lead students of higher education to distinguish and make the best use of new media, which should be used by university students and become the strong carrier for their intellect growth.

\section{References}

[1] Feng Gang, Studying the 18th Report of CPC and Trying to Enhance the Quality of University Students' Ideological and Political Education, Leading Journal of Ideological \& Theoretical Education, 2013, No 1,p44-49.

[2] Sun Han, A Study of Adaptability of Ideological and Political Education in We Media Circumstance, KeJi Jing Ji Shi Chang, 2013, No 9, p95-96.

[3] Fan Yi hua, A Survey of Cultivation of Socialist Core Value of Contemporary University Students in New-Media Age, Science Leading Journal,2016, No7, p112-114.

[4] Zheng Yuanjing, The Exploration of Efficiency of Ideological and Political Education of Higher Education in New Media Circumstance, Leading Journal of Ideological \& Theoretical Education, 2011,No11, p107-109.

[5] Jiang Lei, The Managing Methods of Ideological and Political Education in New Media Age, Theoretic Observation,2013,No11,p. 132-133.

[6] Wang Yong, The Cultivation of Socialist Core Values of University Students in Movable Internet Era, Journal of Guangxi Normal University for Nationalities, 2016, No2, p114-116.

[7] Gu Dongdong, The Ideological and Political Education against New Media Influence, Master Thesis of East China Normal University, 2012, p1-48. 
[8] Hu Qiming. The Exploration of Internet Use in New Media Transmission in Higher Education, Southeast Communication, 2014,No7,p 103-104.

[9] Sang Li. Identification Issue of the Progress and Outlook of Socialist Core Values Since 18th Report of CPC, Tribune of Study, 2016,No5,26-28.

[10] Tang Shijun. The Exploration of Subjective Cognition Trend and Practice in Socialist Core Values, Education and Vocation, 2016,No1,p43-45. 